\title{
Editorial
}

\section{Clues from hypercalcaemia}

\author{
S Nicholson' and J Waxman*,I \\ 'Department of Cancer Medicine, Faculty of Medicine, Imperial College of Science, Technology \& Medicine, Hammersmith Campus, Du Cane Road, London \\ WI 2 ONN, UK
}

DOI: $10.1038 /$ sj/bjc/6600220 www.bjcancer.com

(c) 2002 Cancer Research UK

The conundrum of hypercalcaemia in malignancy occurring in the absence of extensive bony metastases was finally solved in the late 1980s with the identification and cloning of PTHrP (parathyroid hormone-related protein) and the history of this discovery is summarised by Martin and Suva (1988). Original work in cell lines and a renal tumour was followed by the identification of PRHrP in a wide variety of malignances (Honda et al, 1988). PTHrP raises serum calcium and stimulates osteoclast activity, leading to bone destruction. This seemed to suggest a simple sequence of events, but malignancy, bony metastasis and hypercalcaemia are linked by mechanisms more subtle than any single linear chain of cause and effect. PTHrP shares eight of its first 13 amino acids with PTH (Mangin et al, 1988). This structural homology leads to shared receptor binding. There are biochemical differences in the effects of these two hormones. PTHrP is a more potent inhibitor of caliuria and promoter of phosphaturia than PTH. Circulating PTHrP is undetectable in health but present in around $80 \%$ of patients with humoral hypercalcaemia. Tissue expression of PTHrP is far more extensive than PTH, and this is reflected in a range of functions beyond calcium homeostasis (Strewler, 2000). The presence of PTHrP in the uterus and the stomach, coupled with its ability to relax smooth muscle, has led to the assertion that, in these tissues at least, it is PTHrP which is the true physiological effector molecule (Martin, 1996). The role of PTHrP in placental calcium transport seems, similarly, to imply far greater functional importance than that of PTH. It is the role of PTHrP in cartilage development, however, which may reveal its significance to the progression of malignant disease. When chondrocytes form new bone they first proliferate then produce the basic extracellular matrix which will be later invaded by cellular components of bone. The chondrocytes then apoptose. The absence of PTHrP, in PTHrP knock-out mice, leads to failure of proliferation and early apoptosis (Amizuka et al, 1996). This protection of chondrocytes from apoptosis in the physiological setting is mirrored in cancer, where transfection of PTHrP into cell lines confers resistance to apoptotic stimuli (Dougherty et al, 1999).

PTHrP stimulates osteoclastic bone resorption. Studies in breast cancer have shown that PTHrP is expressed in most breast primaries and bony metastases, but to a lesser extent in visceral metastases (Powell et al, 1991). The question then arises whether
PTHrP is not merely a marker for bony metastases but also prognostic factor for progression. Animal experiments using a PTHrPexpressing cell line and blocking monoclonal antibody have demonstrated the importance of PTHrP in progression to metastatic bone disease (Guise et al, 1996), while cell culture work indicates that PTHrP can function as a transforming growth factor. There is, then, a high index of suspicion in breast cancer that PTHrP is a key factor in the development of bony metastases.

Prostate cancer has a different natural history to breast cancer. Hypercalcaemia is uncommon in prostate cancer and metastases are predominantly osteoblastic. It is important to realise, however, that the osteoblastic response seen in prostate cancer is preceded, at a cellular level, by osteoclast activation. The difference between breast and prostate, therefore, is not that osteoclast activation occurs or does not occur, but rather that in prostatic metastases an intense osteoblastic reaction is also present (Roodman, 2001). Elegant experiments using in vivo inocculation of paired transfected and untransfected cell lines have, furthermore, indicated a greater metastatic potential for the transfected lines (Rabbani et al, 1999) mirroring the results in breast cancer.

The paper by Bryden et al. (2002) in this issue of the journal extends observations of PTHrP expression in other tumours to prostate cancer. The authors have demonstrated a high rate of concordance for the expression of both PTHrP and its receptor in paired primary tumours and bony metastases. The ultimate purpose of studies such as these is either to identify new markers of prognostic importance, or to provide a mechanistic explanation of disease progression which may yield new therapeutic targets. The high frequency of expression in primary prostate cancers would seem to indicate that PTHrP is a poor discriminator of metastatic potential. However, the sample sizes are small, and larger studies linking PTHrP expression to outcome are required to demonstrate any prognostic significance of this observation. The role of experimental therapeutics directed against PTHrP may seem nonsensical, since the numerous factors which come into play by the time metastatic bone disease has developed implies that there is no role for PTHrP-directed intervention. If, however, a link between PTHrP and progression to bone disease is established, then targetting the PTHrP at earlier disease stages might eventually lead to a change in the natural history of prostate cancer. 


\section{REFERENCES}

Amizuka N, Henderson J, Hoshi K, Warshawsky H, Ozawa H, Goltzman D, Karaplis A (1996) Programmed cell death of chondrocytes and aberrant chondrogenesis in mice homozygous for parathyroid hormone-related peptide gene deletion. Endocrinology 137: 5055-5067

Dougherty K, Blomme E, Koh A, Henderson J, Pienta K, Rosol T, McCauley L (1999) Parathyroid hormone-related protein as a growth regulator of prostate carcinoma. Cancer Res 59: 6015-6022

Guise T, Yin J, Taylor S, Kumagai Y, Dallas M, Boyce B, Yoneda T, Mundy G (1996) Evidence for a causal role of parathyroid hormone-related protein in the pathogenesis of human breast cancer-mediated osteolysis. J Clin Invest 98: $1544-1549$

Honda S, Yamaguchi K, Suzuki M, Sato Y, Adachi I, Kimura S, Abe K (1988) Expression of parathyroid hormone-related protein mRNA in tumors obtained from patients with humoral hypercalcemia of malignancy. Jap $J$ Cancer Res 79: 677-681

Mangin M, Webb A, Dreyer B, Posillico J, Ikeda K, Weir E, Stewart A, Bander N, Milstone L, Barton D (1988) Identification of a cDNA encoding a parathyroid hormone-like peptide from human tumor associated with humoral hypercalcaemia of mailgnancy. Proc Natl Acad Sci 85: 597-601
Martin T (1996) Actions of parathyroid hormone-related peptide and its receptors. New Engl J Med 335: 736-738

Martin T, Suva L (1988) Parathyroid hormone-related protein: a novel gene product. Baillieres Clin Endocrinol Metab 2: 1003-1029

Powell G, Southby J, Danks J, Stillwell R, Hayman J, Henderson M, Bennett R, Martin T (1991) Localization of parathyroid hormone-related protein in breast cancer metastases: increased incidence in bone compared with other sites. Cancer Res 51: 3059-3061

Rabbani S, Gladu J, Harakidas P, Jamison B, Goltzman D (1999) Overproduction of parathyroid hormone-related peptide results in increased osteolytic skeletal metastasis by prostate cancer cells in vivo. Int J Cancer 80: $257-264$

Roodman G (2001) Biology of osteoclast activation in cancer. J Clin Oncol 19: $3562-3571$

Strewler G (2000) The physiology of parathyroid hormone-related protein. New Engl J Med 342: 177-185 